\title{
Lead Generation: Sowing the Seeds for Future Success
}

\author{
Konrad H. Bleicher, Matthias Nettekoven, Jens-Uwe Peters, and René Wyler*
}

\begin{abstract}
Lead generation and the associated hit-to-lead process are key strategic elements in modern pharmaceutical research, and most companies have implemented this concept. Efficient lead generation is one of the main attempts to reduce the high attrition rates observed along the drug discovery process by focussing on the early developmental phases. The level of integration of the lead generation activities within the discovery organization, the flexibility in assessing and implementing new chemistries and new technologies, the high-quality standards set for the identification of the best possible chemical lead series will ultimately determine the future success in discovering new medicines.
\end{abstract}

Keywords: Lead generation · Lead series · Parallel synthesis · Privileged structures · Targeted libraries

\section{Introduction}

Lead Generation [1] as a Way to Reduce Late Phase Attrition Rates

All pharmaceutical companies have experienced the painful loss of NCEs (new chemical entities) in late stage pre-clinical or clinical development phases. Such latestage failures are costly [2], both in terms of money and time [3]. A detailed analysis of the combined numbers available from both in-house and external sources indicates that roughly one third of the projects fail to enter the lead optimization phase [4], but of the ones that successfully pass this developmental stage, $95 \%$ never end up as drugs on the market due the above-mentioned late-stage failures (Fig. 1).

Efforts and measures to minimize this attrition rates are taken at every stage of the development. The goal of our lead generation efforts is to increase the chances for a program transitioning into the LO-phase (lead optimization phase) to proceed into clinical development and ultimately to reach 'the market'.

\footnotetext{
${ }^{\star}$ Correspondence: Dr. R. Wyler

F. Hoffmann-La Roche Ltd

Pharmaceuticals Division

Lead Generation

$\mathrm{CH}-4070$ Basel

Tel.: +4161688 7224

Fax: +41616886459

E-Mail: rene.wyler@roche.com
}

\section{Lead Generation at Roche Basel}

\subsection{The Position of Lead Genera- tion within Discovery Chemistry}

Besides the two medicinal chemistry sections dealing with the lead optimization phases in the central nervous system (CNS) area and the cardio-vascular/metabolic diseases $(\mathrm{CV} / \mathrm{met})$ area respectively, we have created a lead generation chemistry section
(Fig. 2) which handles all tasks associated with early phase medicinal chemistry. A project in lead generation is initiated upon the identification of 'Hits' [5] either by high-throughput screening (HTS) [6], rational design, or inspired by literature information. After an intensive period of hitvalidation and hit-evaluation, the identification of more than one lead series is our goal. On average this lead series identification

\section{Pharma R\&D metrics of success}

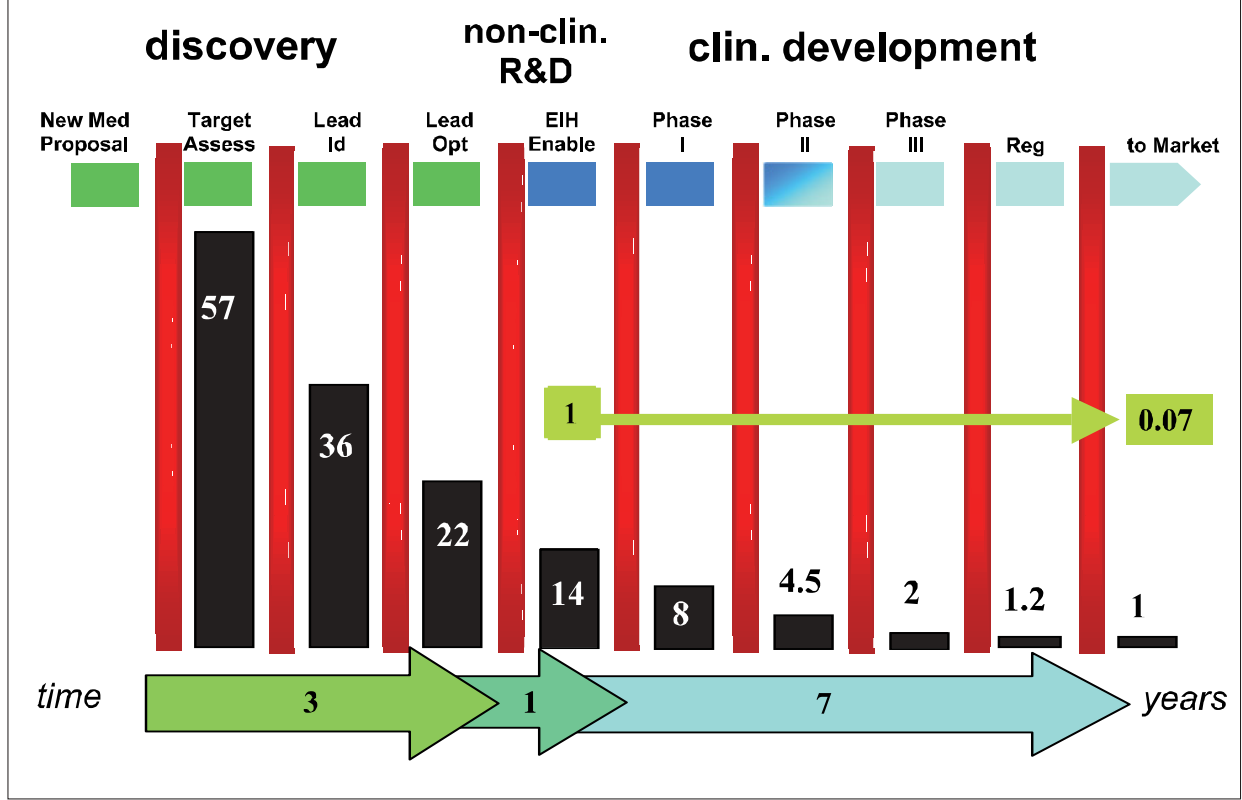

Fig. 1. Average attrition rates from early discovery to market launch 


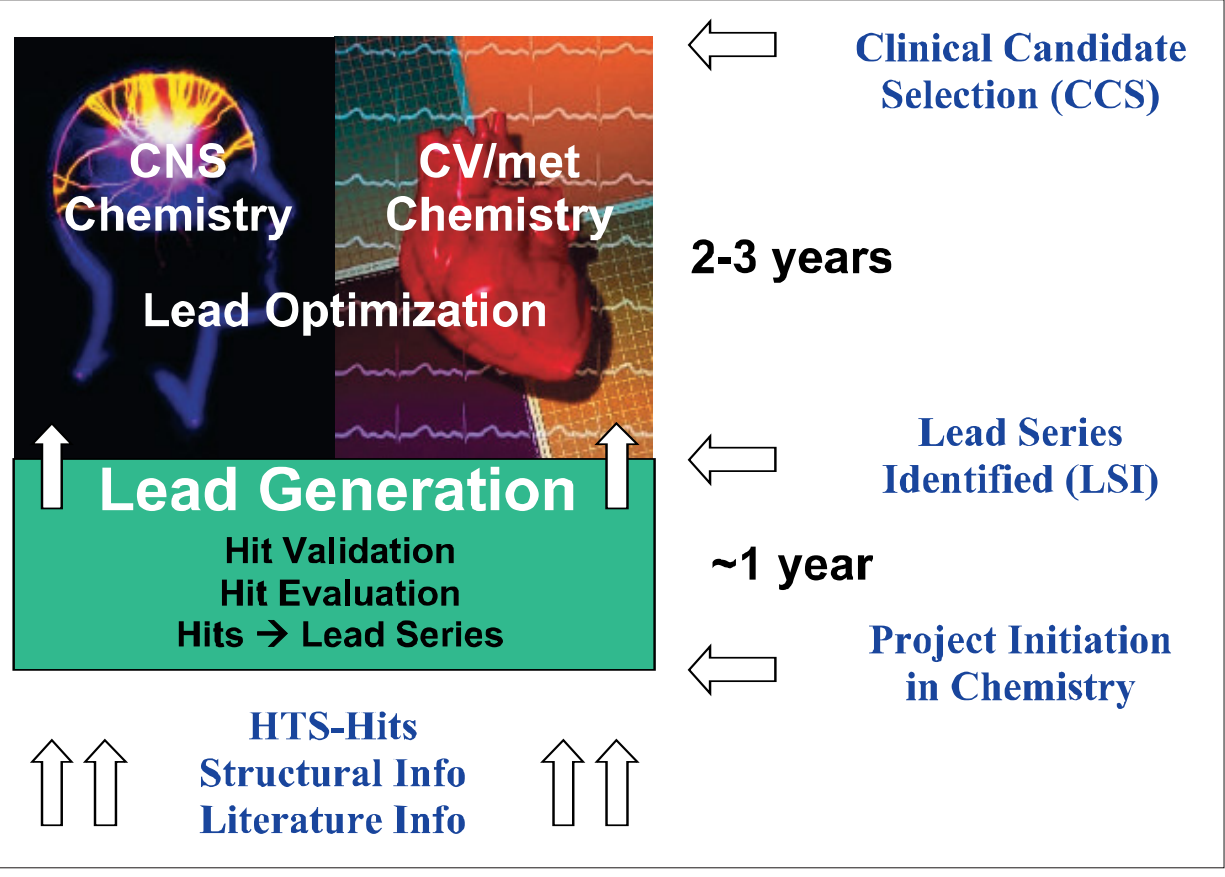

Fig. 2. The drug discovery process in chemistry at Roche Basel process takes about a year for a team of 2-3 chemists. At this stage the project is entering lead optimization (LO) and within 2-3 years, a clinical candidate with the potential to be submitted to human clinical trials $(\mathrm{EIH})$ is usually identified.

To ensure a smooth transition from LI into $\mathrm{LO}$ and to define this milestone, we have implemented a set of stringent quality criteria (Table 1). The indication and/or disease specific criteria are agreed upon at the initiation of the project between the lead generation chemist and the lead optimization chemist who, at this point in time already is part of the project team, will take over the project at the end of the lead generation phase. This has to be agreed upon with the responsible biologists in charge of the pharmacology. The achievement of the LSI milestone based on the defined criteria is peer-reviewed for maximal independence in the assessment of the progress made since hit-finding. However, the criteria agreed upon at the initiation of the project remain dynamic in nature and will, if necessary and beneficial, be adapted as soon as more knowledge becomes available. The quality lead series which display an enhanced likelihood to be further progressed into LO and beyond.

Starting from the original hits, it is usually relatively simple to obtain 'optimized' molecules even if the desired level of potency may not be reached in all cases. Being able to determine accurately and reliably, and as early as possible the mode of

\subsection{The Roche Lead Series Identified Criteria (LSI-Criteria)} emphasis here lies on the delivery of high- action (nature of binding: competitive, noncovalent, etc.), the activity in a cell-based assay (agonistic properties, antagonistic properties, etc.) and the selectivity towards related or other relevant targets is a key asset in efficiently moving a programme ahead. If the first optimization rounds are successful, the 'best' molecules are profiled in a broad panel of enzymes, receptors and channels to identify potential flags to monitor during the later optimization phases. In addition, we have included a series of criteria centred on 'bioavailability' [7]. Physicochemical parameters like solubility, permeability and lipophilicity are also measured and/or calculated in the highest possible throughput mode to ensure the best series with only minimal liabilities are identified early in the hit-to-lead process. Only in exceptional cases optimization efforts will be initiated in series with low solubility $(<1 \mu \mathrm{g} / \mathrm{ml}$ at physiological $\mathrm{pH})$, as we have experienced major difficulties later in the development of such series. In parallel with their physicochemical properties the drug-drug interaction potential of all new series is assessed by measuring CYP450 inhibition for the most relevant iso-enzymes. Poor or insufficient metabolic stability/DMPK-profile being one of the main causes for the high attrition rate in drug development, metabolic stability determination experiments are now routinely conducted as part of our screening cascades, and microsomal stability (and in some cases hepatocyte-stability) is used to guide the optimization of all our lead series. To complete the picture, a full in vivo PK profile for representative examples of each series is determined. The early availability of a suitable in vivo animal model is essen-
Table 1. The Roche lead series identified criteria (LSI-Criteria)

- POTENCY: Effective against the target in the $\mathrm{nM}$ or $\mathrm{mM}$ range, nature of binding (competitive binding, or non-covalent etc...)

- SAR: Potency range spanning over two log units, chemical feasibility

- ACTIVITY in cell-based assays (agonist/antagonist?)

- SELECTIVITY against other receptor subtypes, no "polypharmacology'

- PHYS. CHEM. PROPERTIES: Acceptable solubility $(e . g .>5 \mu \mathrm{g} / \mathrm{ml})$, permcability (medium/high), lipophilicity, protein binding, ...

- DRUG-DRUG Interaction potential: e.g. IC50 for CYP3A4 and others $>10 \mu \mathrm{M}$

- DMPK in vitro: Metabolic stability in liver microsomes (medium to high with MAB $>50 \%$ ). Low clearance in hepatocytes

- DMPK in vivo: Acceptable profile (half life, bioavailability, clearance, brain/plasma ratio if indicated...)

- Activity In vivo: Signs of activity in an in vivo model at 'reasonable doses'

- SAFETY/TOXICITY: No major in silico alerts, early in vitro tests (mutagenicity, phototoxicity, phospholipidosis, hERG not systematically activc...)

- NOVELTY: Patentable series 
tial for the identification of high-quality lead series, and our LSI-criteria specify the need for such a model to be established. Safety aspects are also considered during the hit-to-lead process, by identifying potential liabilities and in silico alerts and by measuring selected parameters (hERGpotassium channel activity, mutagenicity, etc.) in all series. Last but not least, and certainly earlier on, all our efforts need to focus on patentable series. Extensive literature searches are often necessary to determine the patentability of a novel lead series, and this is becoming increasingly difficult. The fierce competition among pharmaceutical companies, academic institutions and biotechs leaves less and less space to patent proprietary compounds. Navigating safely around large claims from existing patents or other publications can be a real challenge and needs a high level of creativity both from the chemistry and from the patenting side. Some of our earlier lead series had to be abandoned due to the impossibility to secure a safe intellectual property position.

Achieving all of the described requirements within a lead series is not a trivial endeavour, but the challenge to reach an LSI milestone has also had a beneficial impact on the way projects are selected and initiated. By raising the awareness of all scientists involved in the process, more impact is given to the 'chemical feasibility' and to the 'drugability' of the target(s) of interest. The resources are thus spent on chemical series that have a higher chance of successfully completing later optimization rounds.

\subsection{The Optimization Process in Lead Generation}

The rapid and most complete possible characterization of the hits is a key element in designing a proper optimization strategy. The properties to be improved need to be identified and the corresponding assays with a sufficient throughput for parallel op- timization need to be available early on in the discovery process. A tailored screening cascade is then implemented to address the compound specific issues with the goal to gradually transform the original hits into high-quality lead series with an overall profile matching the desired target product profile (TPP). This multi-dimensional optimization strategy (MDO) takes advantage of the simultaneous assessment of key parameters at the same time. This enables the project team to arrive at decisions whether to pursue or abandon certain molecules or hit series more rapidly based on profound data sets (Fig. 3).

This approach of evolving the original hits into high-quality lead series is not always successful and it is preferable to abandon a series or even a project if the desired criteria cannot be met already in this early phase, thus allowing for the redistribution of the resources to other series or projects, ultimately resulting in an increased overall success rate. We have also learned that the identification of more than one lead series either in parallel or in a sequential manner to generate back-up series has proven beneficial. A switch from the first series to a back-up series can be triggered either by unexpected difficulties in the lead optimization phase or by the discovery of a superior class of compounds in terms of overall profile.

The following section deals with recent examples of successful hit-to-lead chemistry in the area of CNS- and cardiovascular-metabolic diseases chemistry. The first section will exemplify a strategy that was followed using privileged scaffolds to generate both hits and leads and its application in the field of G-protein coupled receptors (GPCRs). Subsequently, the endeavour to arrive at conclusive structure-activity relationships within a certain heterocyclic scaffold is exemplified with various triazolopyridine derivatives which proved potentially

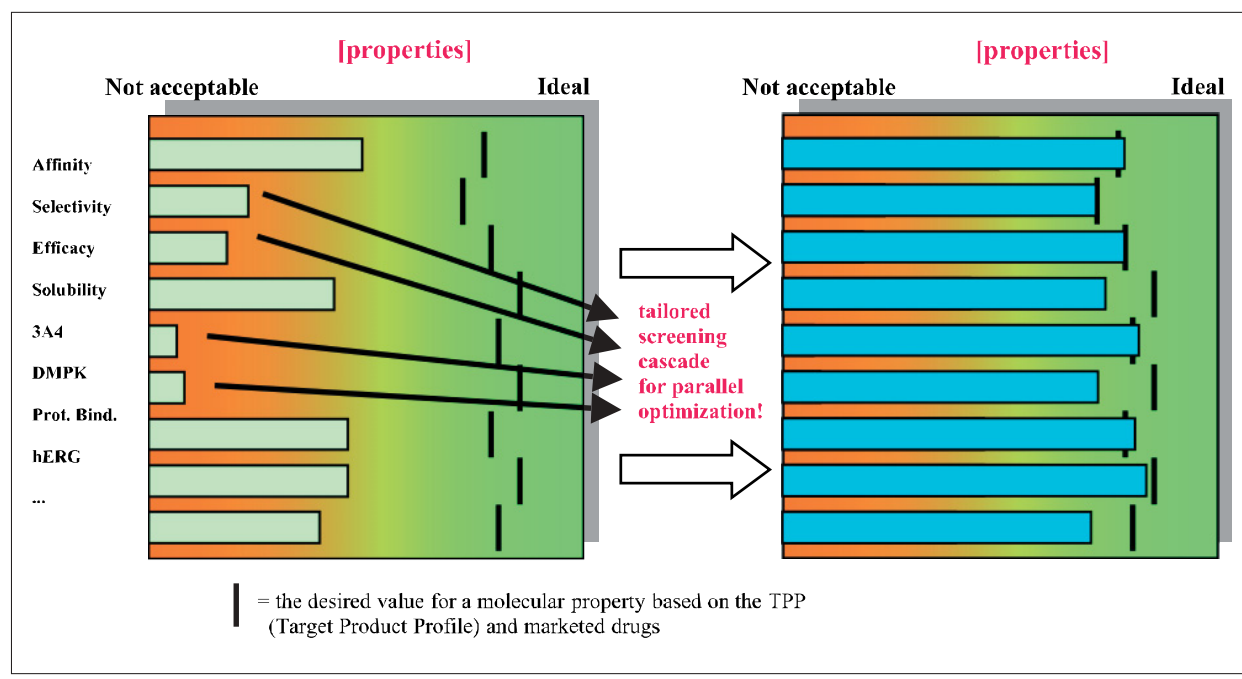

Fig. 3. Optimization of several parameters in parallel (MDO) useful entities to inhibit subtypes of the adenosine receptor family. In another example novel inhibitors of dipeptidyl peptidase IV (DPP-IV) as potential new medicines for the treatment of type 2 diabetes were sought. With the aid of parallel chemistry, high-throughput in vitro assays and computational tools a weakly active screening hit was rapidly developed into a lead series of DPP-IV inhibitors that combine high activities with favourable molecular properties.

\section{Case Studies Within Lead Generation}

\subsection{Identification of Novel NK-1 Receptor Ligands via Privileged Structure-Based Library Design}

High-throughput screening has developed into a well-established methodology within the early drug discovery phase of both big pharmaceutical companies as well as specialized small biotechs. In fact most of the research projects where chemistry is initiated deliver the first starting points from massive random screening of large compound inventories. The luxury of hit lists and compound clusters identified via HTS are highly appreciated in the chemistry community. Nevertheless tedious follow-up work is necessary such as hit confirmation by re-ordering/synthesis of compounds, their quality assessment as well as structural confirmation to name but a few. Lead generation chemists are dealing with these issues on a routine basis to generate as much information as possible from an HTS campaign before follow-up chemistry is started. High-throughput screening is particularly interesting for targets where no biostructural- or patent data is available and for such projects where the 'unexpected' is intended to add benefit on the development of a research program. Nevertheless screening capacity is not unlimited. Although the actual testing phase might be very short (100 $000 \mathrm{cpds} /$ day) and the costs per data point fairly low (0.1-1 US\$) protein preparation, assay development, compound purchasing and logistics etc. all add to the HTS overhead. In addition, increasing compound inventories both in quality and quantity, constantly upcoming novel targets and requested selectivity screening campaigns are setting clear limits for this approach. It is obvious that there is a need for complementary technologies which allow the initiation of chemistry programs either in addition to the HTS route or without any random screening method.

One such alternative source to generate novel hits besides the random screening approach of huge compound collections is the biased screening of so-called targeted libraries. The design of compound collec- 


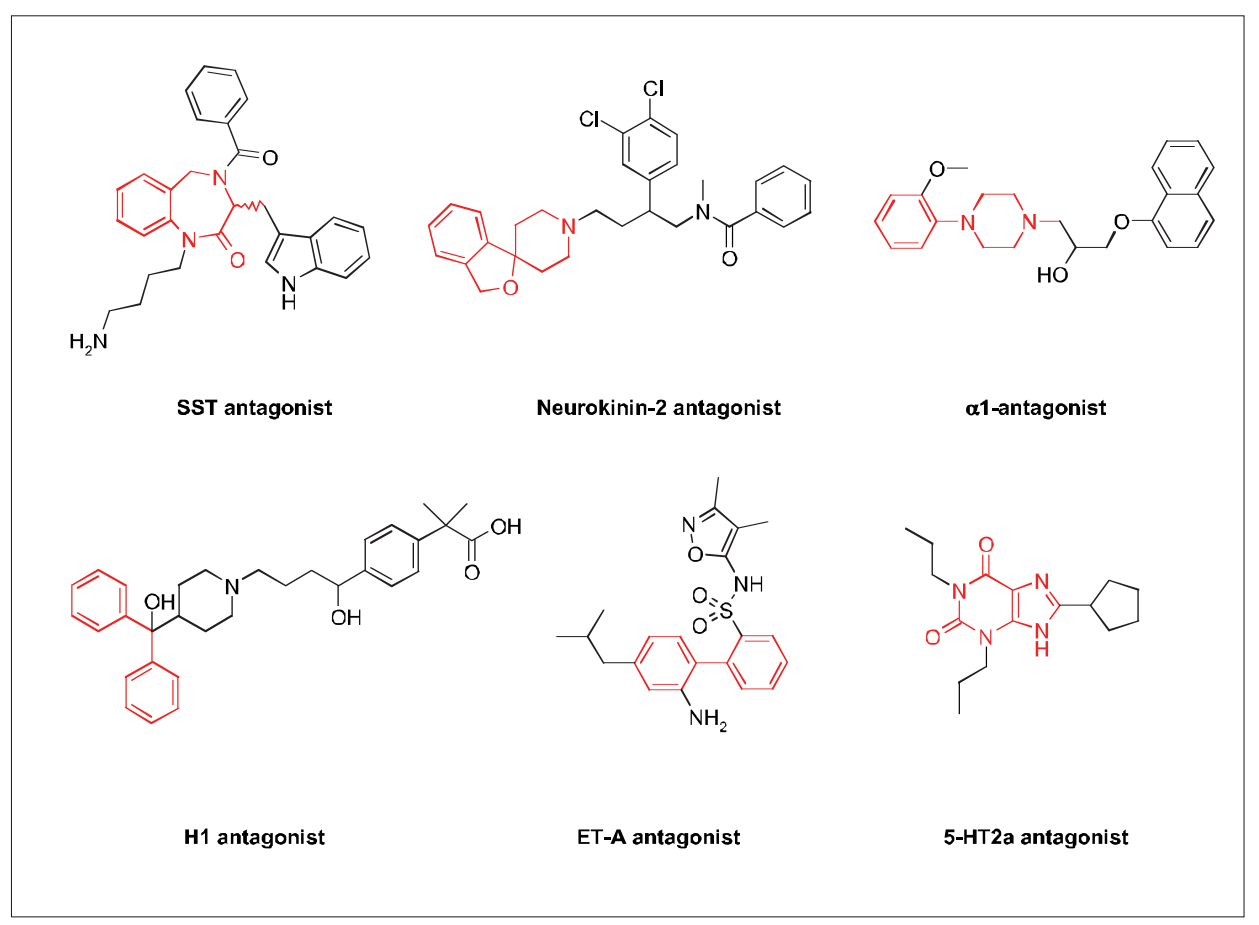

Fig. 4. Privileged GPCR structures (highlighted in red) as promiscuous elements of protein ligands

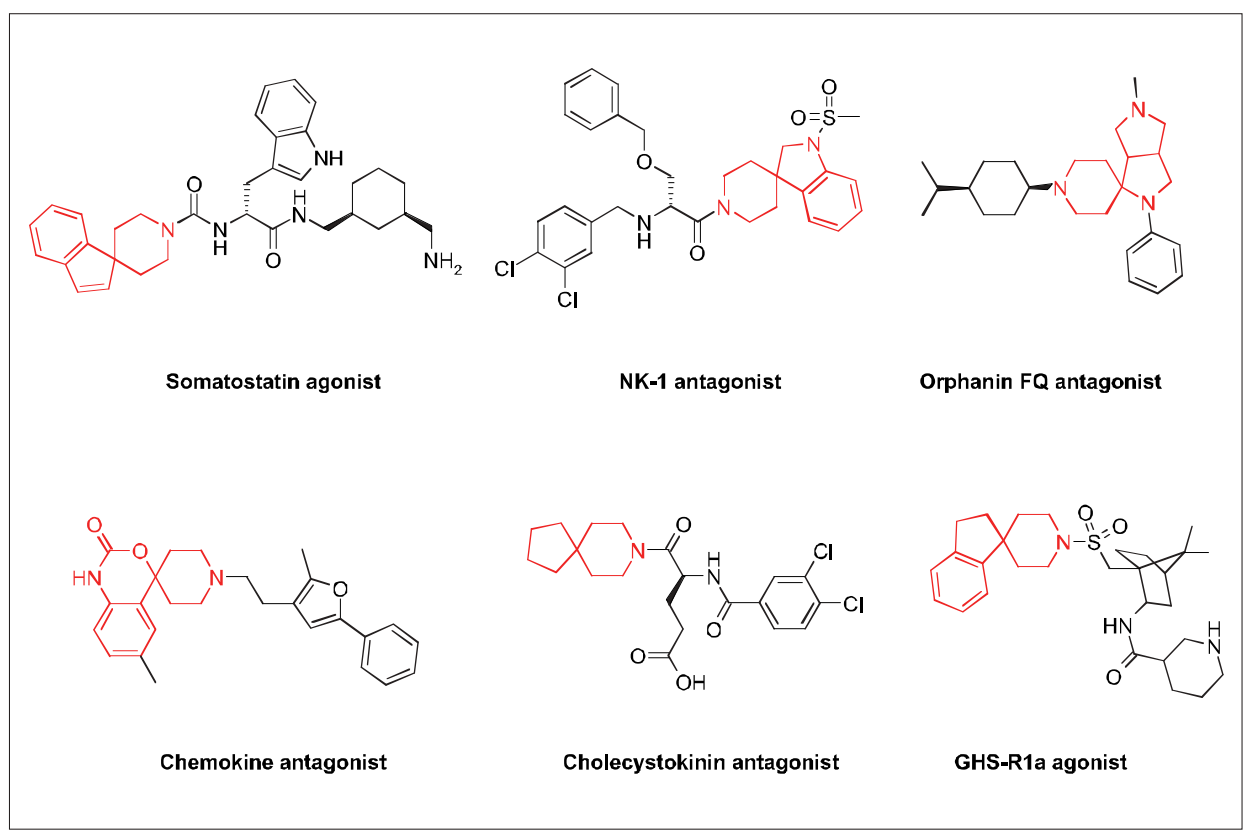

Fig. 5. Various spiropiperidines as privileged structures for reported GPCR ligands

tions is essential in this regard to result in compound arrays showing higher hit rates for particular protein families compared to others. Where for random screening campaigns an average hit rate of $c a .0 .1-1 \%$ can be observed (this is very much dependent on the target screened and the threshold set) targeted libraries must deliver much higher hit rates to be competitive with the HTS approach. Various design methodologies have been reported where the privileged structures approach seems to be most widely ap- plied currently. Especially in the area of Gprotein coupled receptors (GPCRs), where the lack of biostructural information drives alternative approaches, several successful projects have been disclosed [8]. Nevertheless it is still unclear which molecular features are required for a chemotype to result in a privileged structure and how such chemotypes are recognized by the target proteins. Although speculations about common binding sites [9] and 'first contact' motives at the surface of the proteins [10] have been discussed, a clear understanding on the binding event of privileged structures to their proteins is still lacking.

A number of privileged structures are discussed as depicted in Fig. 4. Exemplified are six different chemotypes representing ligands for GPCRs.

One very prominent chemotype of such privileged structures are the spiropiperidines, which have been widely reported in the literature. Some examples are shown below (Fig. 5).

In contrast to the 'privileged structure', the terminus 'needle' was described in the literature as a fragment of an active molecule showing very specific interactions with one particular biological target. One very well-known example for such a needle within the GPCR area is the ortho-substituted biphenyl tetrazole (or bioisosteres), an element present in most angiotensin-1 antagonists currently on the market [11].

In our efforts towards identifying novel small-molecule ligands targeting the neurokinin receptor (NK-1) we initiated a focused library synthesis based on the design strategy to combine the two concepts of 'privileged structures' and 'needles'. The neurokinin receptors belong to the target family of 7-transmembrane G-protein coupled receptors [12][13]. Due to the size and the high lipophilicity of such membranebound receptors the isolation and crystallisation of such target proteins is extremely difficult. Therefore biostructure-based library design is currently limited, leading us to employ a ligand-based library design approach. For the neurokinin receptors three subtypes have been identified so far (NK-1, NK-2, and NK-3). They are expressed in the periphery (mainly NK-2) as well as in the central nervous system (NK-1 and NK$3)$. Hence their therapeutic utility ranges from CNS indications to the potential treatment of respiratory and gastric diseases. The endogenous ligands for the neurokinin receptors are the tachykinins, a group of peptides that all share a common C-terminal amino acid sequence Phe-X-Gly-LeuMet- $\mathrm{NH}_{2}$ where $\mathrm{X}$ is either Phe or Val. The most prominent member of this peptide family is the undecapeptide 'Substance P' ( $\mathrm{X}=\mathrm{Phe}$ ) which shows highest affinity for the NK-1 receptor, whereas NKA and NKB $(\mathrm{X}=\mathrm{Val})$ are both decapeptides that bind preferentially to the NK-2 and NK-3 receptor, respectively. Although GPCRs with such large peptide ligands as natural substrates are supposed to be rather difficult to be modulated by small molecules, several drug-like NK-1 receptor modulators have been reported in the literature where some of the representatives are depicted in Fig. 6.

Besides the fact that these molecules again represent some of the well-known privileged structures (e.g. methylene biphenyl- or arylpiperidines) many of the 
<smiles>CC(=O)N[C@@H](Cc1c[nH]c2ccccc12)C(=O)OCc1cc(C(F)(F)F)cc(C(F)(F)F)c1</smiles>

L-732,138

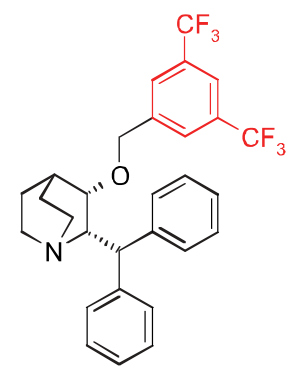

L-709,210

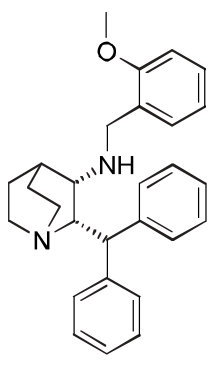

CP-96,345

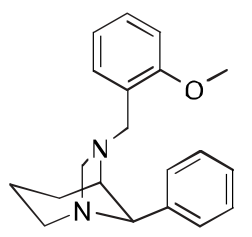

CP-211,754

Fig. 6. Reported NK-1 receptor ligands

reported NK-1 ligands show the 3,5-bistrifluoromethyl phenyl motif (highlighted in red) which is meanwhile well-recognized as an 'NK-1 needle'. With that information in hand we considered generating small compound arrays based on several spiropiperidine scaffolds (privileged GPCR structures) and adding the 3,5-bistrifluoromethyl phenyl (NK-1 needle) to further decorate the remaining exit vectors randomly. Instead of extensively exploiting the chemotype by analoging each exit vector in the templates we decided to either concentrate on one additional modification or employ only relatively small building blocks to keep the molecular weight and the resulting lipophilicity in an appropriate range.

The first compound arrays were based on the spirohydantoin template. These compounds can be rapidly generated from the corresponding amino acid. Starting from commercially available 4-aminopiperidone the orthogonally protected 4aminopiperidine-carboxylic acid was therefore generated. The NK-1 needle was either introduced via the benzyl chloride at the $\alpha$ amino acid nitrogen 1a, the corresponding benzoic acid at the piperidine nitrogen $\mathbf{1 b}$, or the aniline or -benzylamine at the imide nitrogen 1c, respectively. The final compounds were generated using both parallel solution- and Merrifield-resin based solidphase chemistry as reported elsewhere (Table 2) [14].

For all three possibilities where the NK1 needle directs to either the northern, southern or western part of the template,<smiles>CC(O[C@H]1OCCN(Cc2n[nH]c(=O)[nH]2)[C@H]1c1ccc(F)cc1)c1cc(C(F)(F)F)cc(C(F)(F)F)c1</smiles>

L-754030

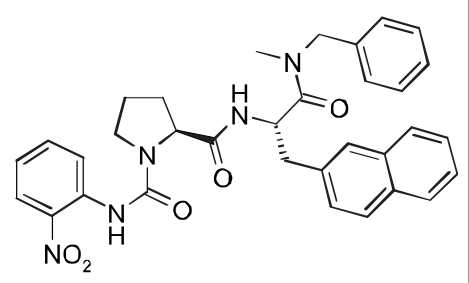

SDZ NKT-343 ligands were identified that showed decent affinities ( $\mathrm{pKi}>5$ ) in a radioligand displacement assay. The highest affinity ligands generated are disclosed below (Table 2) : 2a-o. From a set of 136 compounds, 97 ligands showed a binding affinity of $\mathrm{pKi}(\mathrm{hNK}-1)>5$ which corresponds to a hit rate of $71 \%$.

Table 2. Spirohydantoin as NK-1 receptor ligands

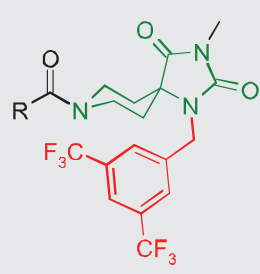

1a

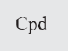

2a<smiles>[R]</smiles><smiles>Cc1cccc2ccccc12</smiles>

2b<smiles>Cc1c(Cl)cccc1Cl</smiles>

$2 \mathrm{c}$<smiles>Cc1ccccc1F</smiles>

2d<smiles>CCN1CC(=O)N(c2ccc(OC)c(OC)c2)C1</smiles>

2e

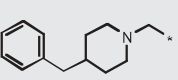<smiles></smiles>

$1 \mathrm{~b}$
As a second example we started from the correspondingly orthogonal protected or resin-bound spiropyrrolo-pyrrole. This template was identified by us in the orphanin FQ (OFQ) area; a target protein that belongs to the superfamily of peptide class 1 GPCRs. Again the fairly specific NK-1 needle was introduced into the scaffold at all three possible positions $\mathbf{3 a - c}$ and the remaining vectors decorated using solutionand/or solid-phase chemistry [15].

As already observed for the spirohydantoins, independent of the position of the NK-1 needle within the spiropyrrolo-pyrrole template various low nanomolar binding molecules were obtained. From an array of 132 compounds submitted for testing, 91 ligands were identified with a binding affinity of $\mathrm{pKi}(\mathrm{hNK}-1)>5$, resulting in a hit rate of $69 \%$. Fifteen representatives are depicted in Table 3 (4a-o).

The two examples discussed above exemplify the application of privileged structure-based library design for the generation of small-molecule GPCR ligands. As powerful as this technique can be, it is obvious that the search for novel privileged structures and/or needles is essential. De novo design tools such as Skelgen [16] or TOPAS [17] have been described that allow socalled scaffold hopping, a method to move into novel and therefore patent-free chemotypes. Although affinity is usually the first indication of a valuable compound class, other properties such as selectivity, function, solubility and many more are equally important. 
Table 3. Spiropyrrolo-pyrrols as novel NK-1 receptor ligands.

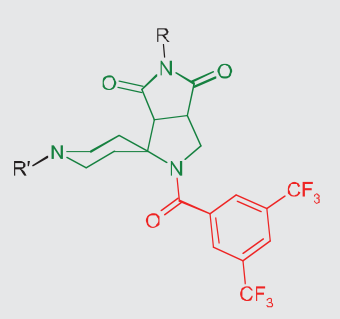

$3 \mathbf{a}$

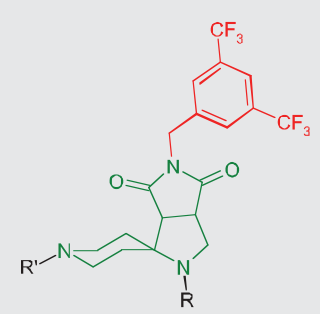

3b

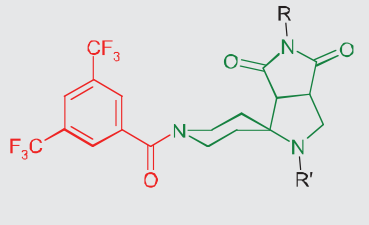

$3 c$

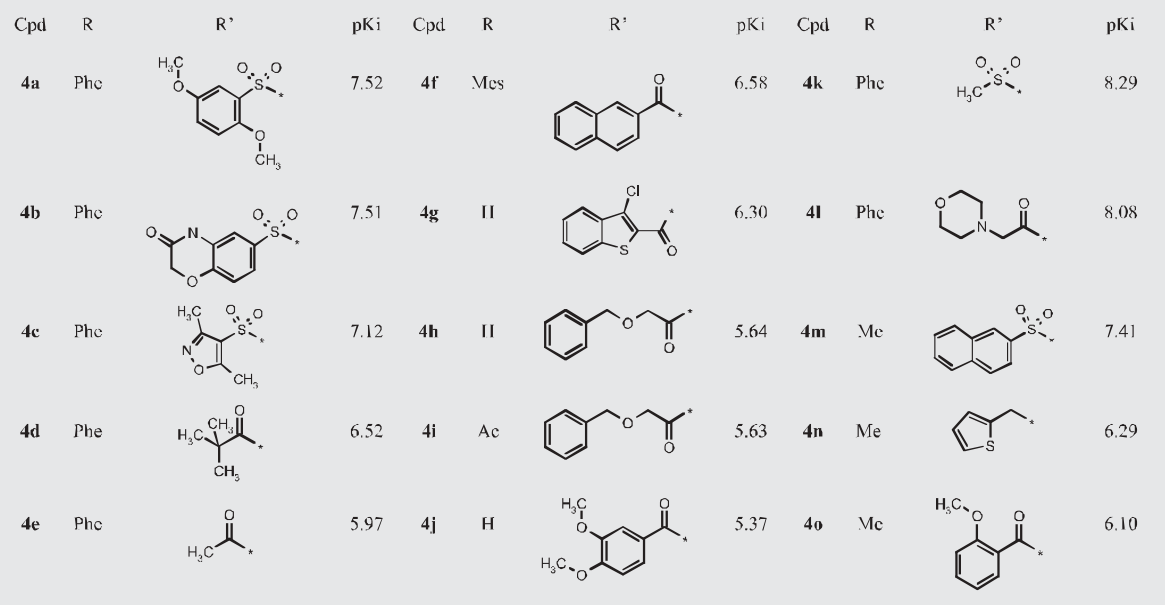

\subsection{Establishment of SAR with Triazolopyridine Derivatives as Potential Inhibitors of Receptors of the Adenosine Family}

In a recent medicinal chemistry project, triazolopyridine derivatives attracted considerable attention since such molecules were identified from HTS as potential inhibitors of adenosine receptor subtypes. The main focus was centered on the identification of potent inhibitors of the adenosine $2 \mathrm{a}(\mathrm{A} 2 \mathrm{a})$ receptor which were required to be selective against the adenosine 1 (A1) receptor under the assumption that they possess the potential to modulate neuro- degenerative diseases (e.g. Parkinson, Alzheimer, depression) and therefore allow for a new entry into the regulation of behavioural disorders [18]. The previously described [19] synthesis of 7-amino-triazolopyridines afforded the desired compounds only in very moderate overall yields due to the harsh reaction conditions employed and a more generally applic(two steps). action sequence was sought [20]. Chelidamic acid (5) can be conveniently brominated in the 4-position by phosphorous pentabromide and upon quenching of the intermediate with ethanol; the desired 4brominated di-ethyl ester $\mathbf{6}$ was isolated in

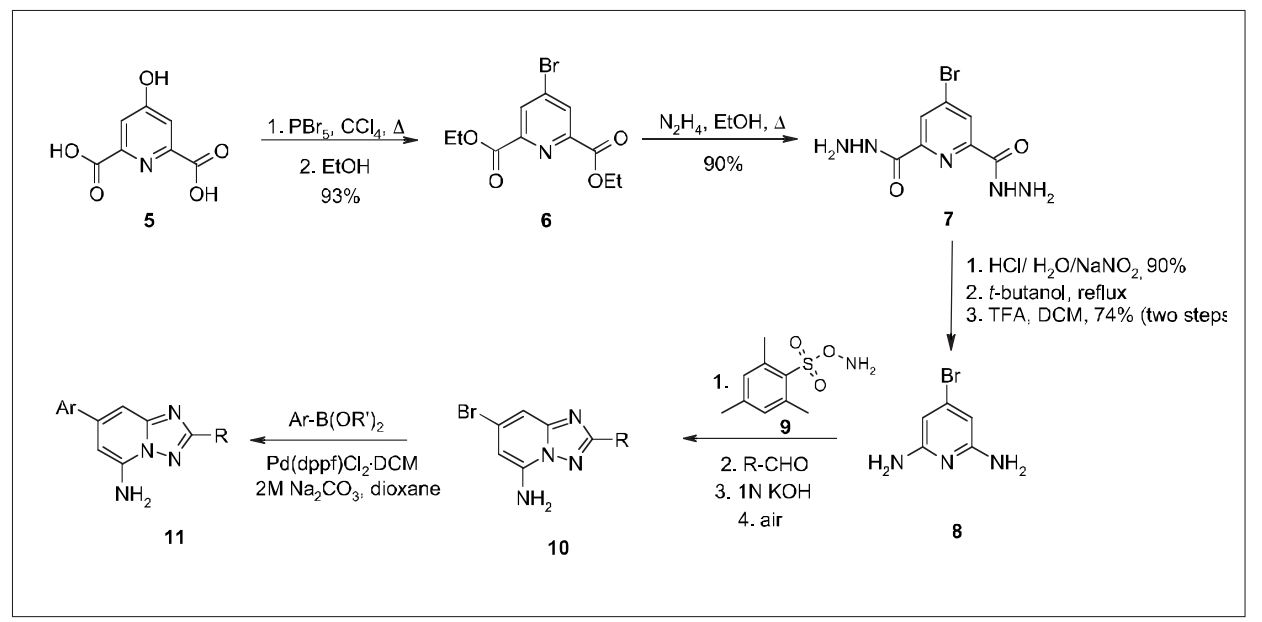

Scheme 1. Synthetic access to 7-amino-triazolopyridine derivatives $\mathbf{1 1}$
93\% yield [21]. Conversion of the ester functionalities to yield the bis-hydrazide 7 was achieved by treatment with hydrazine hydrate in $90 \%$ yield in pure form after crystallisation. Subsequently, diazotisation of 7 was smoothly accomplished by treatment with $\mathrm{NaNO}_{2}$ under acidic conditions in $90 \%$ yield. The double Curtius rearrangement, was triggered by heating the intermediate in $t$-butanol under reflux and subsequent elaboration of the isocyanates to bis $\mathrm{N}$ - $t$-butoxycarbonyl pyridine, which was not isolated, and after removal of excess $t$-butanol was treated with excess TFA in DCM to liberate the desired 2,6-diamino4-bromopyridine (8) in $74 \%$ yield after crystallisation. The subsequent amination of the pyridine-nitrogen was successfully achieved by employing O-mesitylenesulfonylhydroxylamine (9) as an aminating source. The reaction with various substituted benzaldehydes, substituted furan-carboxaldehydes, substituted thiophene-carboxaldehydes, substituted pyridine-carboxaldehydes as well as cycloaliphatic aldehydes proceeded smoothly and upon addition of aqueous $\mathrm{KOH}$ and exposure of the reaction vessel to ambient air, an efficient cyclisation and oxidation took place to obtain the triazolopyridines $\mathbf{1 0}$ in yields up to $79 \%$. The final Suzuki reaction was performed under the preferred method employing $\mathrm{Pd}(\mathrm{dppf}) \mathrm{Cl}_{2} \cdot \mathrm{DCM}$ as catalyst and aqueous sodium bicarbonate in boiling dioxane. Boronic acids and boronic esters worked equally well in the cross-coupling reaction and the desired products $\mathbf{1 1}$ were isolated in yields up to $49 \%$ (Scheme 1).

A library of 260 triazolopyridine derivatives $\mathbf{1 1}$ were synthesised using the late step Suzuki reaction as described. All products were tested in an in vitro radioligand displacement assay against the human A2a and $\mathrm{A} 1$ receptor. Based on these results, partially shown in Table 4 , a preliminary structure-activity relationship was deduced and the influence of Ar and R could be examined. Derivatives like 11a $(\mathrm{R}=$ phenyl) display a moderate activity towards A2a and the selectivity towards A1 was also insufficient. In comparison derivatives with $\mathrm{R}$ = furyl $(\mathbf{1 1 b}-\mathbf{c})$ show a much higher affinity towards A2a with IC50s recorded in the low nanomolar range. The selectivity towards the A1 receptor reached $2 \log$ units, however was found to be strongly dependent on the nature of Ar. In order to circumvent the potential metabolic instability of the unsubstituted furyl-derivatives potentially more stable compounds like $\mathbf{1 1 d}-\mathbf{f}$ ( $\mathrm{R}$ = 2-methyl-furyl) were characterised. In general the affinity towards A2a was diminished but the selectivity was retained. Other heterocyclic surrogates like thiophenyl 11g, pyridinyl $11 \mathrm{~h}$ and methoxy-thiophenyl $\mathbf{1 1} \mathbf{i}-\mathbf{j}$ proved to be less potent. Partially saturated heterocyclic compounds like $11 \mathbf{k}-\mathbf{l}$ 
Table 4. Binding affinities towards A2a and selectivities for A1 for selected triazolopyridines 11

I1]
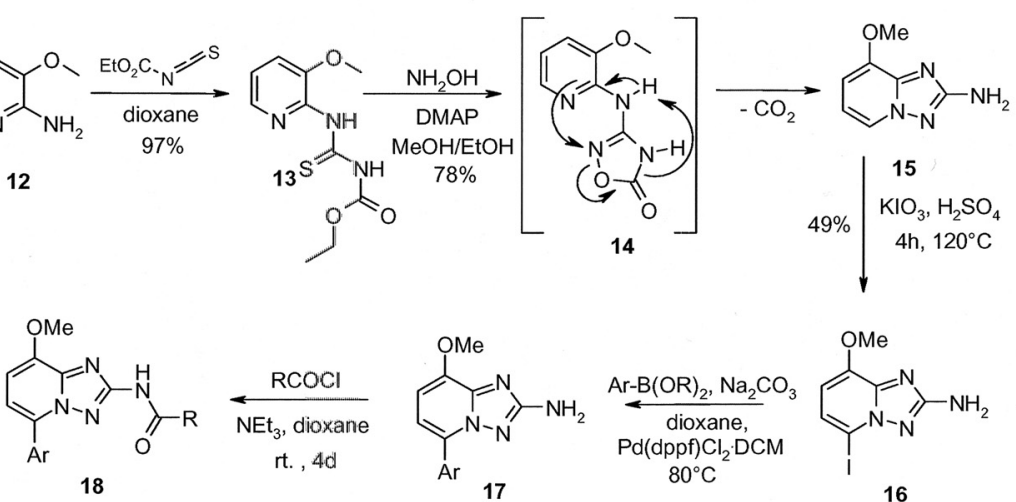

16

Scheme 2. Synthetic access to 8-methoxy-[1,2,4]triazolo[1,5-a]pyridine derivatives 18

Table 5. Binding affinities towards A2a and selectivities for A1 for selected 2-amido-5-aryl-8methoxy-triazolopyridine derivatives 18

IC50 (A2a) $\begin{gathered}\text { Selectivity } \\ \text { [nM] }\end{gathered}$

displayed no advantage in comparison to the previously described compounds.

A complementary synthetic approach allowed access to novel triazolopyridine derivatives with a substitution pattern different to the one described for the compounds already examined [21]. To the best of our knowledge, synthetic access to 5-aryl-8methoxy-[1,2,4]triazolo[1,5-a]pyridines $\mathbf{1 8}$ has not been described, however structurally related compounds have been identified as potential herbicidial agents [22]. Therefore, 2-amino-3-methoxy pyridine (12) was reacted with ethoxycarbonyl isothiocyanate to yield almost quantitatively the thiourea derivative 13 which was subjected to a cyclisation procedure, transitioning via the proposed intermediate 14, employing hydroxylamine and DMAP in a protic solvent to afford 8-methoxy-triazolopyridine $\mathbf{1 5}$ in $78 \%$ yield. Regioselective iodination of $\mathbf{1 5}$ with $\mathrm{KIO}_{3}$ in sulfuric acid yielded iodotriazolopyridine 16, in $49 \%$ yield, which conveniently underwent Suzuki coupling reactions with a set of 34 boronic acids or esters. Reaction conditions employing $\mathrm{Pd}(\mathrm{dppf}) \mathrm{Cl}_{2} \cdot \mathrm{DCM}$ in dioxane with sodium carbonate as base at elevated temperatures furnished the 5-aryl-8-methoxy-triazolopyridine derivative $\mathbf{1 7}$ in yields up to $82 \%$. The amidation of $\mathbf{1 7}$ with acid chlorides under prolonged reaction times concluded this five-step synthetic sequence giving access to a range of desired triazolopyridines $\mathbf{1 8}$ with yields up to $61 \%$ (Scheme 2).

The obtained compounds were tested in in vitro radioligand displacement assays against the human A2a and A1 receptor. Unfortunately, all the compounds isolated displayed an insufficient potency and selectivity profile. The most potent compound $\mathbf{1 8 k}$ showed an IC50 of $110 \mathrm{nM}$ with a selectivity of 36. Preliminary structure-activity relationship of the new triazolopyridine derivatives with such substitution pattern led to the termination of this series (Table 5).

Although we established a novel, straightforward route to aminotriazolopyridines we concentrated our efforts towards the identification of triazolopyridines with improved binding properties. Based on initial results regarding the initially studied 7amino-triazolopyridines derivatives an extension of this substitution pattern was sought. Instead of an aryl moiety in the 5position a carboxamide moiety was deemed interesting instead [23]. A straightforward reaction sequence was devised starting from 2,6-diamino-pyridine carboxylic acid methyl ester (19) [24]. The adduct resulting from $\mathrm{N}$-amination of $\mathbf{1 9}$ with O-mesitylene-sulfonylhydroxylamine was used directly without further purification in a onepot reaction for the condensation with aldehydes. At elevated temperature the ring-closure took place upon addition of potassium hydroxide in methanol followed 

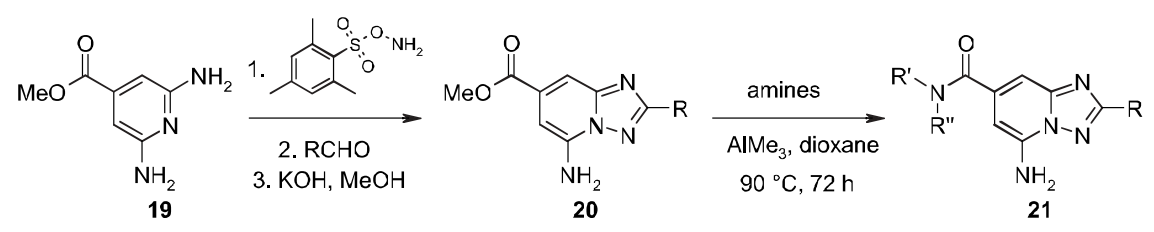

Scheme 3. Synthetic access to 5-amino-2-aryl-[1,2,4]triazolo[1,5-a] pyridine-7-carboxylic acid amide derivatives 21

Table 6. Binding affinities towards A2a and selectivities for A1 for selected 5-amino-2-aryl-[1,2,4]triazolo[1,5-a]pyridine-7-carboxylic acid amide derivatives 21

210

by the final aromatisation initialised by opening of the reaction vessel to ambient air to yield the triazolo-pyridine ester $\mathbf{2 0}$. In total 21 substituted benzaldehydes, furfurals, pyridine carboxaldehydes and thiophene carboxaldehydes were utilised to affect the generation of 1-aryl-substituted triazolo-pyridine methyl esters 20 in satisfactory yields up to $51 \%$ for the threestep/one-pot reaction sequence. The protocol worked reliably for all selected aldehydes, however, the isolated yields of $\mathbf{2 0}$ were dependant on steric and electronic features of the aldehydes which determined their reactivity. The conversion of the ester functionality in the triazolo-pyridine derivatives $\mathbf{2 0}$ to form the desired amide derivatives $\mathbf{2 1}$ was straightforward. The most promising protocol for a clean transformation employed conditions where methylaluminoxane pre-mixed with amines was reacted with the respective esters in dioxane at 90 ${ }^{\circ} \mathrm{C}$ for a prolonged period of time (48-96 h) giving access to the desired triazolopyridine carboxamides $\mathbf{2 1}$ in yields up to $70 \%$ (Scheme 3).

A library of 500 5-amino-2-aryl$[1,2,4]$ triazolo[1,5-a]pyridine-7-carboxylic acid amide derivatives $\mathbf{2 1}$ was synthesised in a combinatorial iterative fashion (typical size of 24-48 members/array) taking ad- vantage of parallel solution-phase chemistry thus allowing for maximal flexibility in chemistry and maximal efficiency in in vitro biological activity optimisation. A representative selection is shown in Table 6.

The synthesised compounds showed varying activity/selectivity profiles and several conclusions could be drawn regarding the structure-activity relationship. Compounds with 6-membered aromatic $\mathrm{R}$ moieties $(\mathbf{2 1 a}-\mathbf{c})$ were only moderately potent and overall showed poor selectivity towards the A1 receptor. Furyl-substituted triazolopyridines like 21d-h started to yield very active compounds with moderate to acceptable selectivities. The influence of steric and electronic properties of various amines in combination with variously substituted furyl-triazolopyridines $\mathbf{2 1 d}-\mathbf{h}$ could be studied and depending on the pattern, compounds with low nanomolar affinities and acceptable selectivity profiles could be identified. Thiophenyl-triazolopyridines, in general, were less active and selective than their furyl-counterparts $\mathbf{2 1 i}-\mathbf{k}$. However, some activity and selectivity could be regained with thiazolyl-triazolopyridine derivatives like $\mathbf{2 1 1}$.

The amines to be employed in the final synthetic arrays were chosen according to diversity considerations and desired physicochemical properties predictions of the end products [25]. A virtual screening procedure based on a topological pharmacophore similarity metric and self-organising maps (SOM) was developed and applied to optimising combinatorial triazolopyridines 21. The starting point for this was a set of 153 combinatorial products derived from scaffold structure 21 (Fig. 3) with known Ki values for the two adenosine receptor subtypes A2a and A1. With this information a preliminary structure-activity relationship (SAR) model was built, which could be used to virtually synthesize novel combinatorial products with improved activity and selectivity for the A2a receptor. For the identification of 'best-suited' building-blocks a novel virtual screening procedure based on artificial neural networks was followed (self-organizing maps, SOM [26] and topological pharmacophore similarity (CATS method) [27]):

1. Encoding the set of tested compounds by the CATS method

2. Training of a SOM for feature mapping (SAR model) (Fig. 7)

3. Identification of 'seed' compounds from the SOM

4. Variation of the seed by virtual library enumeration

5. Projection of the virtual library onto the SOM obtained by step 2

6. Selection of candidates for synthesis and testing (focused library design)

7. Chemical synthesis and determination of in vitro activity

8. Go to step 1, or terminate

With the exception of step 7 of this scheme, optimisation takes place in silico.

A single synthetic optimisation round based on two seed structures which populated mainly neuron (4/3) and neuron (5/3) (Scheme 4) was performed and a small focused library of 17 selected combinatorial products was synthesised and tested.

On average, the synthesised compounds based on this design cycle yielded a threefold smaller binding constant ( 33 vs. $\sim 100$ $\mathrm{nM}$ ) and 3.5 fold higher selectivity (50 vs. 14) than the initial library. In general, bromofuryl-triazolopyridine derivatives 21m-r show binding affinities in the low nanomolar range with a decent to good selectivity. Thiazolyl-triazolopyridine derivatives 21s-v were found to be less potent, but still moderately selective. The most selective compound 21p obtained revealed a 121-fold relative selectivity for A2a with $\mathrm{Ki}$ $(\mathrm{A} 2 \mathrm{a})=2.4 \mathrm{nM}$, and $\mathrm{Ki}(\mathrm{A} 1)=292 \mathrm{nM}$. Parts of the results are shown in Table 7.

This result demonstrates that it was possible to design a small, activity-enriched focused library with an improved property profile using the SOM virtual screening approach. This strategy will be further pursued and it might prove particularly useful in projects where structure-based design 
a)

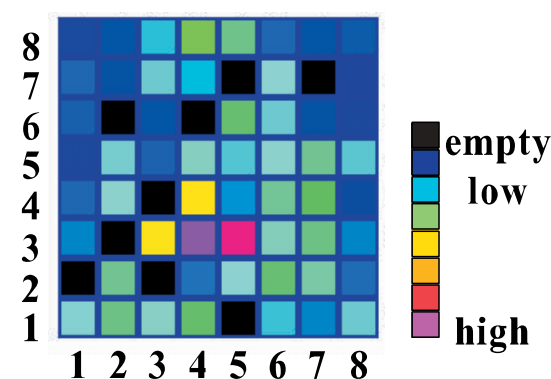

b)

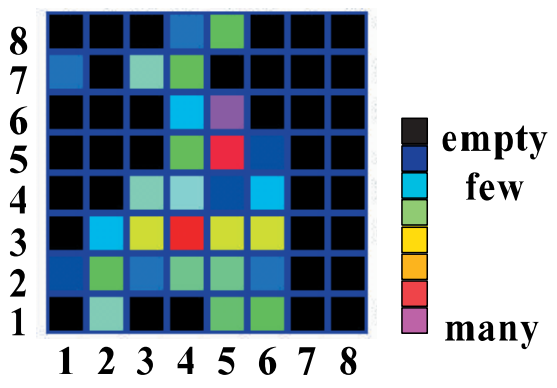

Fig. 7. Self-organising maps showing the distribution of selectivity values, [Ki (A1)/Ki (A2a)], of (a) the initial 153-member library, and (b) the 192 virtually generated combinatorial products<smiles>[R]N([R])C(=O)c1cc(N)n2nc(-c3nccs3)nc2c1</smiles>

seed structure from neuron $(4 / 3)$

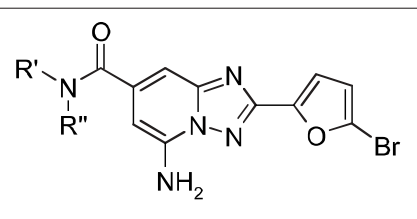

seed structure from neuron $(5 / 3)$
Scheme 4. Seed strucand $(5 / 3)$ tures from neurons $(4 / 3)$

Table 7. Binding affinities towards A2a and selectivities for A1 for selected in silico optimised 5-amino-2-aryl-[1,2,4]triazolo[1,5-a]pyridine-7-carboxylic acid amide derivatives 21

\begin{tabular}{|c|c|c|c|c|c|c|c|c|c|}
\hline No & NR'R', & $\mathbf{R}$ & $\begin{array}{c}\mathrm{Ki}(\mathrm{A} 2 \mathrm{a}) \\
{[\mathrm{nM}]}\end{array}$ & $\begin{array}{l}\text { Selectivity } \\
\text { (A1/A2a) }\end{array}$ & No & NR'R', & $\mathbf{R}$ & $\begin{array}{c}\text { Ki (A2a) } \\
\text { [nM] }\end{array}$ & $\begin{array}{l}\text { Selectivity } \\
\text { (A1/A2a) }\end{array}$ \\
\hline $21 \mathrm{~m}$ & & & 1.7 & 32 & $21 r$ & & & 2.9 & 45 \\
\hline $21 n$ & & & 3 & 65 & $21 \mathrm{~s}$ & & & 87 & 31 \\
\hline 210 & & & 4.4 & 65 & $21 t$ & & & 104 & 19 \\
\hline $21 p$ & & & 2.4 & 121 & $21 u$ & & & 51 & 66 \\
\hline $21 q$ & & & 11.7 & 53 & $21 v$ & & & 84 & 53 \\
\hline
\end{tabular}

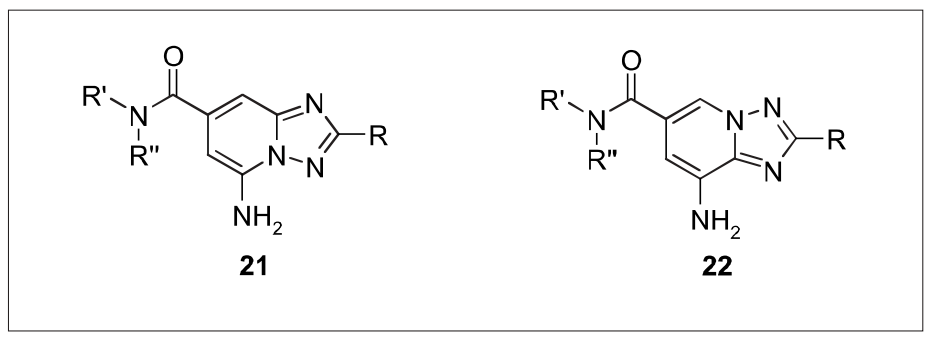

Fig. 8. Isomeric triazolopyridine derivatives 21 and 22
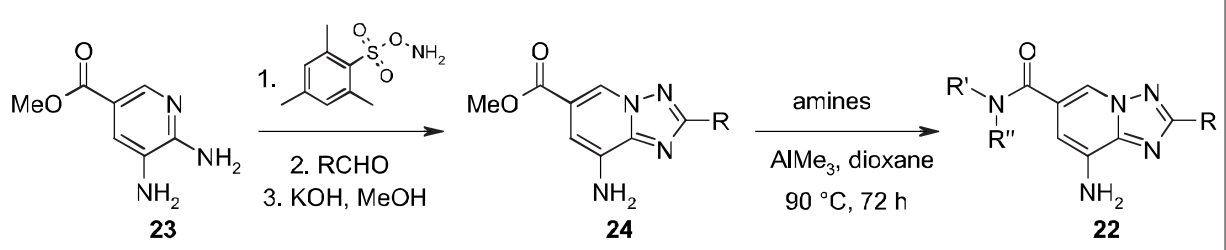

Scheme 5. Reaction sequence towards triazolopyridine derivatives 22 and 24 cannot be applied due to a lack of receptor structure information, e.g. in the many projects aimed at finding new GPCR modulators.

The synthesis of isomeric triazolopyridine derivatives offered another good possibility to receive a deeper insight into the underlying principles which affect binding and selectivity [28]. In this context it appeared particularly interesting to observe any changes in activity/selectivity towards the adenosine receptors for triazolopyridine derivatives $\mathbf{2 1}$ in comparison to $\mathbf{2 2}$ as all main vectors extend from a structurally very similar main scaffold (Fig. 8).

By comparison of binding affinities/selectivities from a set of triazolopyridines $\mathbf{2 1}$ versus the isomeric structures $\mathbf{2 2}$ electronic properties of the main scaffold should mainly contribute towards any adenosine antagonism. The synthesis of the desired triazolopyridine derivatives $\mathbf{2 2}$ followed the well-established general synthetic sequence previously described (Scheme 5).

5,6-Diamino-nicotinic acid methyl ester 23 [29] can be reacted in a three-step onepot procedure with eight different aldehydes to furnish a small array of triazolopyridine carboxylic acid ester derivatives $\mathbf{2 4}$ in yields up to $52 \%$. The desired 8-amino2-aryl-[1,2,4] triazolo[1,5-a]pyridine-6-carboxylic acid amides 22 were conveniently accessed by reacting the respective amine with $\mathrm{AlMe}_{3}$ for $1 \mathrm{~h}$ and subsequently with the ester $\mathbf{2 4}$ in dioxane at elevated temperatures for a prolonged period of time. In total 118 final products were obtained in yields up to $44 \%$. A total of twenty 8-amino-2aryl- $[1,2,4]$ triazolo $[1,5-a]$ pyridine-6-carboxylic acid amides derivatives 22 were obtained which had an isomeric 5-amino-2aryl-[1,2,4]triazolo[1,5- $a$ ]pyridine-7-carboxylic acid amide derivatives counterpart 21. All of the compounds were tested against the human $\mathrm{A} 2 \mathrm{a}$ and $\mathrm{A} 1$ receptor. Part of the results of these isomeric pairs are displayed in Table 7 and reveal that in general triazolopyridine derivatives $\mathbf{2 1}$ have a higher binding affinity towards the A2a receptor and overall have an improved selectivity profile versus A1 (Table 8).

Both scaffolds are very similar with respect to topology, shape and H-bond donor/acceptor regions, but subtle differences in the H-bond donor strength of the amino group influence the affinity towards the $\mathrm{A} 2 \mathrm{a}$ receptor. The molecular modelling software package Moloc provides quantitative descriptors of hydrogen bond donor and acceptors strengths for selected atoms [30]. When the donor and acceptor strengths of the three nitrogen atoms with hydrogen bond donor/acceptor capabilities in the two scaffold series were compared (relative to water: 1.748) it became apparent that donor and acceptor strengths were markedly changed for the amino group and 
Table 8. Binding affinities towards A2a and selectivities for A1 for selected isomeric triazolopyridine derivatives $\mathbf{2 1}$ and $\mathbf{2 2}$

\begin{tabular}{|c|c|c|c|c|c|c|c|}
\hline$\underset{[\mathrm{nM}]}{\mathbf{K i}(\mathrm{A} 2 \mathrm{a})}$ & $\begin{array}{l}\text { Selectivity } \\
\text { (A1/A2a) }\end{array}$ & No & NR'R" & $\mathbf{R}$ & No & $\underset{[\mathbf{n M}]}{\mathbf{K i}(\mathbf{A 2 a})}$ & $\begin{array}{l}\text { Selectivity } \\
\text { (A1/A2a) }\end{array}$ \\
\hline 3 & 68 & $21 w$ & & & $22 a$ & 277 & 8 \\
\hline 8 & 125 & $21 x$ & & & $22 b$ & 40 & 66 \\
\hline 2 & 122 & $21 y$ & & & $22 c$ & 61 & 20 \\
\hline 4 & 36 & $21 z$ & & & $22 d$ & 76 & 19 \\
\hline 57 & 26 & 21 aa & & & $22 e$ & 192 & 19 \\
\hline 11 & 151 & $21 \mathrm{ab}$ & & & $22 f$ & 57 & 74 \\
\hline
\end{tabular}

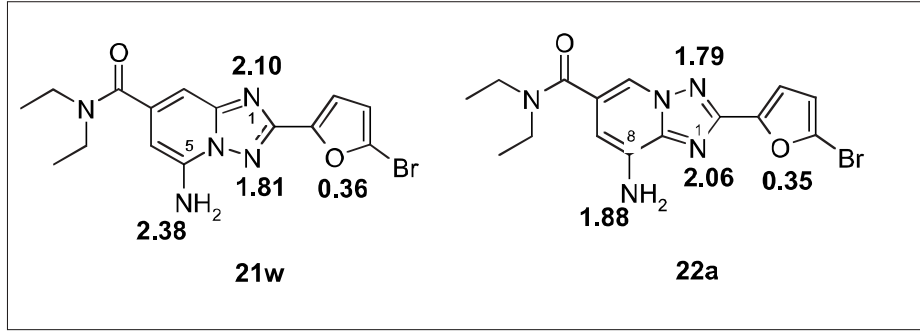

Fig. 9. Exemplified H-bond donor- and $\mathrm{H}$-bond acceptor strengths for selected atoms of $\mathbf{2 1} \mathbf{w}$ compared to $22 \mathrm{a}$

the triazolo nitrogen atom, which is located on the same side as the amino moiety, however, all following the same trend. This can be explicitly exemplified with the two isomers 21w and 22a (Fig. 9).

The H-bond acceptor strength of $\mathrm{N}(1)$ of the 8-amino derivative 22a was relatively higher (approx. 0.35 units) in comparison to the N(3) H-bond acceptor strength of the 5-amino derivative 21w. The H-bond donor strength of the amino group in $\mathbf{2 1 w}$ was markedly higher (approx. 0.5 units) in comparison to the $\mathrm{H}$-bond donor strength of the amino group in 22a. From the correlation of hydrogen bond donor and acceptor strengths of the nitrogen atoms of all isomers in both scaffold series it can be concluded that the generally more pronounced donor strength of the amino group in the 5amino series 21 seemed the main determinant for increased affinity and A2a/A1 selectivity in comparison to the 8-amino series 22. Although both scaffold series are structurally highly similar, subtle changes in the electron density greatly impact the molecular recognition 'event' and cause a difference in biological activity. Thus, the molecular similarity principle ('similar structures, similar bioactivities') [31] should be more precisely formulated as 'similar recognition motifs, similar activities'.

These lead generation activities within a medicinal chemistry program focused solely towards the optimisation of triazolopyridine derivatives in respect to their ability to potently bind to the A2a receptor with a significant selectivity against the A1 receptor. In the course of these endeavours many avenues towards the synthesis of new triazolopyridine derivatives have been explored, established and subsequently utilised with the aid of parallel iterative solution phase chemistry [32]. This approach allowed for the optimal balance between adequate number of compounds prepared and the knowledge content inherent in each new class. The main advantage in the adequate utilisation of automated chemistry devices and procedures can be seen in the shortening of compound synthesis cycle times which in turn allow for a more profound decision event whether to pursue or terminate one compound class over the other. The seamless integration of various molecular modelling activities also yielded synergistic effects since it was possible to arrive at more active and selective triazolopyridine derivatives and on the other hand allowed for further refinement of underlying molecular modelling programs through a more thorough understanding of molecular events.

\subsection{Aminomethylpyrimidines as DPP-IV Inhibitors}

In another project we sought novel inhibitors of dipeptidyl peptidase IV (DPPIV) as potential new medicines for the treatment of type 2 diabetes. DPP-IV cleaves and inactivates glucagon-like peptide 1 (GLP-1) [33], which is an important stimulator of insulin secretion [34]. DPPIV inhibition prevents the degradation of GLP-1 and so indirectly improves the impaired insulin secretion in type 2 diabetic patients [35]. In an HTS campaign of our compound collection, we discovered aminomethylpyrimidine $\mathbf{2 5}$ as a weak inhibitor of DPP-IV.

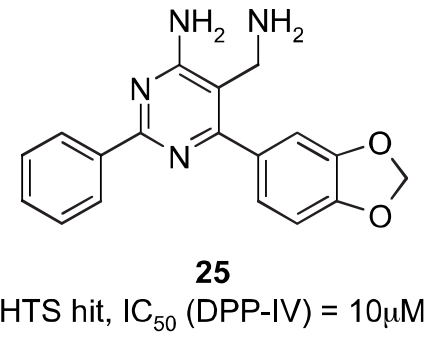

We decided to prepare a number of analogues of this single hit in a parallel chemistry setup to quickly evaluate the potential of this structural class for further optimisation (Scheme 6). Benzylamidine (26) was reacted with a number of arylidenemalononitriles 27 under basic conditions with a subsequent oxidative step [36]. This gave cyanopyrimidines $\mathbf{2 8}$ as intermediates, which were then reduced to the desired aminomethylpyrimidines 29. The working procedures were amenable to parallel solution phase chemistry utilising previously described workflows [32].

The obtained compounds 29 were evaluated for DPP-IV inhibition in a fluorogenic in vitro assay (Table 9). We observed that ortho- and para substitution at the 6phenyl ring generally increased the inhibitory activity, whereas meta substituents had no effect or even decreased the inhibitory activity. An attempt to combine the favourable ortho- and para substitution in one compound resulted in the ortho-paradichloro derivative 30 (Table 10), which had a 1000-fold improved activity compared to the original screening hit 25 [37]. 


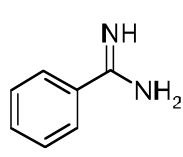

26<smiles>N#CC(C#N)=Cc1ccccc1</smiles>

27

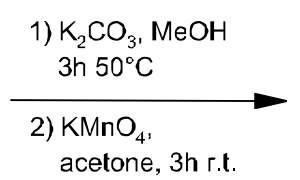

acetone, $3 \mathrm{~h}$ r.t

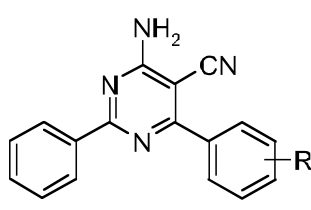

28
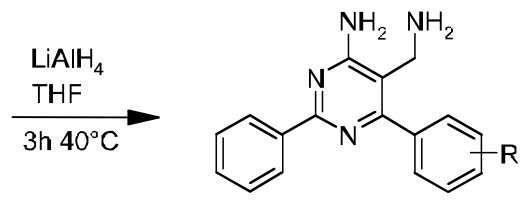

29

Scheme 6. Synthesis of 2-phenylpyrimidines $\mathbf{2 9}$

Table 9. DPP-IV - IC50 [ $\mu \mathrm{M}]$ data for aminomethylpyrimidine derivatives 29

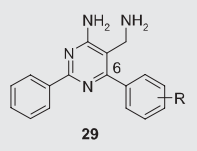

\begin{tabular}{cccccc}
\multicolumn{7}{c}{$\mathrm{R}=\mathrm{H}: 42$} & & \\
$\mathrm{R}=$ & $\mathrm{Me}$ & $\mathrm{Cl}$ & $\mathrm{OMe}$ & $\mathrm{F}$ & $\mathrm{CF}_{3}$ \\
ortho & 1.5 & 2.5 & 1.5 & 14 & 14 \\
meta & 20 & 31 & 80 & 40 & 170 \\
para & 1.0 & 1.4 & 47 & 18 & 1.1
\end{tabular}

Table 10. Properties of $\mathbf{3 0}$

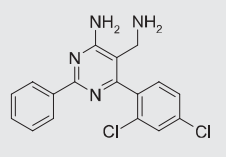

30

$$
\begin{aligned}
\mathrm{IC}_{50}(\mathrm{DPP}-\mathrm{IV}) & =0.01 \mu \mathrm{M} \\
\log _{7.4} & =3.0 \\
\text { solubility } & >0.4 \mathrm{~g} / 1 \\
\mathrm{CL}_{\text {int }}{ }^{\mathrm{a}} & =5 \mu \mathrm{l} / \mathrm{min} / \mathrm{mg}
\end{aligned}
$$

$\mathrm{IC}_{50}(\mathrm{CYP} 3 \mathrm{~A} 4)=5.4 \mu \mathrm{M}$

- causes phospholipidosis in vitro

ahuman liver microsomes

Having shown that high inhibitory activity can be achieved, we next turned our attention to the molecular properties of this structural class. Several representatives of this series were profiled in a number of high-throughput in vitro assays. As exemplified by the properties of $\mathbf{3 0}$ (Table 10), the compounds had generally high solubility [38], medium to high stability in rat and human liver microsome preparations [39], and showed good permeation through an artificial membrane (PAMPA assay) [40]. These results indicated a potential for good pharmacokinetic properties of this class. However, in subsequently performed in vitro assays, 30 was found to inhibit CYP3A4 [41] and to cause phospholipidosis (a phospholipid storage disorder) in cultured fibroblasts [42].

These latter findings raised safety concerns because CYP3A4 inhibition is a major cause of drug-drug interactions [43], and phospholipidosis can potentially lead to a variety of adverse effects [44]. Therefore we decided to address these issues with a second series of compounds 33a-g (Table
11), in which we replaced the 2-phenyl substituent by a variety of amino substituents. These compounds were predicted by computational tools to be less lipophilic (KOW_ClogP) [45] and less amphiphilic (CAFCA) [46] than 30 (amphiphilicity describes the tendency of a molecule to orient itself in an environment such as a phospholipid bilayer). Since lipophilicity is a recognition criterion for CYP3A4 [47], and amphiphilicity is predictive for phospholipidosis [48], we speculated that such compounds would be less likely to show CYP3A4 inhibition and phospholipidosis. We obtained these compounds in a parallel fashion from a common building block $\mathbf{3 1}$, which was reacted with a choice of suitable amines to give cyanopyrimidines $\mathbf{3 2}$ [49], which were then reduced to aminomethylpyrimidines 33a-g (Scheme 7).

An evaluation of these compounds in our fluorogenic DPP-IV inhibition assay revealed even sub-nanomolar inhibitors (33b, 33f, Table 11) [50]. However, we found $\mathbf{3 3 g}$ to have the most appealing balance between inhibitory activity and calculated lipophilicity and amphiphilicity, and profiled this compound in the above-mentioned in vitro assays. As documented in Table $12, \mathbf{3 3 g}$ is comparable to $\mathbf{3 0}$ with regard to inhibitory activity, solubility, permeability, and microsomal stability. $\mathbf{3 3 g}$ has a much reduced lipophilicity $(\log \mathrm{D})$ [51], shows a sufficiently reduced CYP3A4 inhibition, and does not induce phospholipidosis in cultured fibroblasts up to the highest test concentration of $20 \mu \mathrm{M}$. Thus, parallel chemistry, high-throughput in vitro assays and computational tools were used to rapidly evolve a weakly active screening hit, 25, into a lead series of DPP-IV inhibitors, 33, that combine high activities with favourable molecular properties.

\section{Conclusion and Outlook}

The level of integration of the lead generation chemistry unit within the rest of the organization and its ability to actively share information with all the partners in the lead identification phase are crucial aspects in discovering the best leads. Rapid feed-back loops within the project, the ability to collect, understand, integrate and interpret the enormous amount of data generated in parallel since the early days of the project constantly need to be optimized. At all levels in the chain 'small' but essential improvements have tremendously helped in this respect: The implementation of a corporate database capturing all of the above-mentioned data, the installation of a 'liquid master store' to handle and process orders of up to one thousand 'cherry-picked' compounds from the HTS-group or the lead generation chemists to probe early SAR, the 'geographical concentration' of all disciplines within one site to allow also for personal contacts between the scientists on top of sharing data in the electronic format, the constant efforts to miniaturize all the measurements to reduce the consumption of the precious molecules of interest, the steady increase in the throughput of most of the essential tests to give just a few examples. As demonstrated in this review, the clear criteria for the identification of an LSI also contribute to streamline the whole process and to limit the time spent on 'less promising' series as well as to guide the target selection towards more tractable or 'drugable' project even before initiation. Chemistry is still the main driving force behind any lead identification process and constant efforts need to be made to continuously increase the understanding of medicinal chemistry aspects on top of the general chemical and synthetic expertise. The quality of the equipment

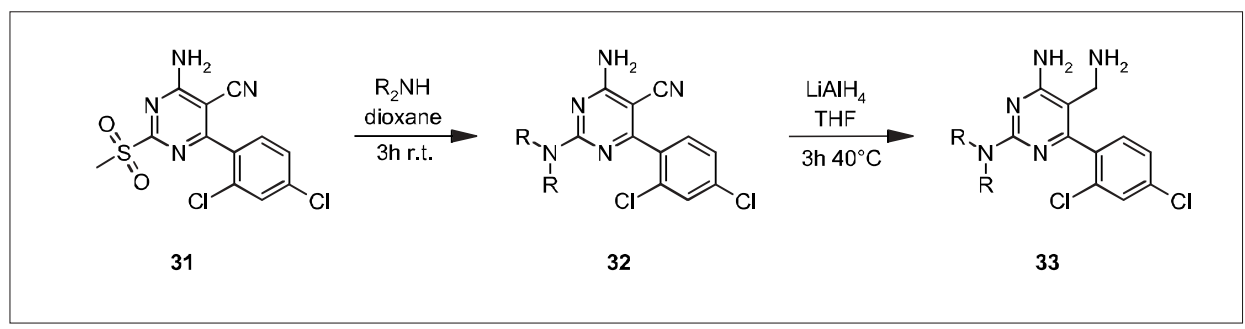

Scheme 7 . Synthesis of 2-aminopyrimidines 33 
Table 11. Inhibitory activity and in-silico values of aminomethylpyrimidines 33 (in comparison to $\mathbf{3 0}$ ). Lipophilicity (KOW_ClogP) was regarded as a contributing factor to CYP3A4 interaction, and amphiphilicity $\left(\Delta \Delta \mathrm{G}_{\mathrm{AM}}\right)$ as a measure of phospholipidosis potential.<smiles>[R]c1nc(N)c(CN)c(-c2ccc(Cl)cc2Cl)n1</smiles>

\begin{tabular}{|c|c|c|c|c|}
\hline & $\mathrm{R}=$ & KOW_ClogP & $\begin{array}{c}\Delta \Delta \mathrm{G}_{\mathrm{AM}} \\
(\mathrm{kJ} / \mathrm{mol})\end{array}$ & $\begin{array}{c}\mathrm{IC}_{50}(\mathrm{DPP}-\mathrm{IV}) \\
(\mu \mathrm{M})\end{array}$ \\
\hline 30 & $\mathrm{Ph}$ & 2.6 & -6.6 & 0.01 \\
\hline $33 a$ & & 1.4 & -5.3 & 0.14 \\
\hline $33 \mathbf{b}$ & & 2.3 & -5.7 & 0.0002 \\
\hline $33 c$ & & 1.8 & -5.6 & 0.011 \\
\hline 33d & & 2.2 & -5.7 & 0.024 \\
\hline $33 e$ & & 2.3 & -5.8 & 0.055 \\
\hline $33 f$ & & 0.9 & -6.0 & 0.0005 \\
\hline $33 \mathrm{~g}$ & & 1.6 & -5.6 & 0.009 \\
\hline
\end{tabular}

Table 12. Properties of $\mathbf{3 3 g}$

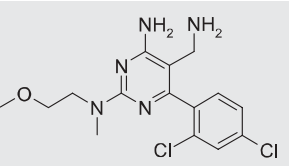

$33 \mathrm{~g}$

$$
\begin{aligned}
\mathrm{IC}_{50}(\mathrm{DPP}-\mathrm{IV}) & =0.009 \mu \mathrm{M} \\
\log \mathrm{D}_{7.4} & =1.6 \\
\text { solubility } & >0.6 \mathrm{~g} / 1 \\
\mathrm{CL}_{\text {int }}^{\mathrm{a}} & =4.9 \mu \mathrm{l} / \mathrm{min} / \mathrm{mg}
\end{aligned}
$$$$
\mathrm{IC}_{50}(\mathrm{CYP} 3 \mathrm{~A} 4)=30 \mu \mathrm{M}
$$

- no phospholipidosis in vitro

ahuman liver microsomes

available to the chemical community, the level of automation and the possibility to access novel laboratory and in silico technologies has also steadily improved recently, as major investments were made (and continue to be made) in these fields.

Lead generation has matured over the years and has become an integral part of the drug discovery process. Since hit-to-lead activities are unavoidably connected with the collection, validation and interpretation of considerably large data sets it will be- names appear in the references and whose contributions made the described work possible and so enjoyable. The authors also would like to thank Dr. A.W. Thomas for helpful discussions during the preparation of the manuscript. Prof. Dr. K. Müller and Dr. G. Adam are thanked for the donation of schemes.

Received: July 1, 2004

[1] a) A. Alanine, M. Nettekoven, A.W. Thomas, E. Roberts, Comb. Chem. High Throughput Screen. 2003, 6, 51; b) W.F. Michne, Pharma News 1996, 3, 19; c) S. Campbell, E. Differding, Chim. Nouv. 2001, 19, 3347; d) A. Tropsha, C.H. Reynolds, J. Mol. Graph. Mod. 2002, 20, 427; e) A.D. Baxter, P.M. Locky, Drug Discovery World 2001, 2, 9; f) D. Hunter, J. Cell. Biochem. 2001, Suppl. 37, 22; g) M.H. Hann, T.I. Oprea, Curr. Opinion Chem. Biol. 2004, 8, 255; h) M.J. Sofia, Drug Disc. Today 2004, 9, 293-295.

[2] a) J.A. Dimasi, Clin. Pharmacol. Therap. 2001, 69, 297; b) N.D. Shah, L.C. Vermeulen, J.P. Santell, R.J. Hunkler, K. Hontz, Am. J. Health-System Pharm. 2002, 59, 131.

[3] a) M. Zall, Modern Drug Discovery 2001, 4, 36; b) M. Zall, Modern Drug Discovery 2001, 4, 41; c) E. Ratti, D. Trist, Il Farmaco 2001, 56, 13; d) A.E.P. Adang, P.H.H. Hermkens, Curr. Med. Chem. 2001, 8, 985.

[4] Parexel's Pharmaceutical R\&D Statistical Sourcebook, 2002, 102.

[5] a) J. Knowles, G. Gromo, Nature Rev. Drug Discov. 2003, 2, 63; b) B.R. Roberts, Targets 2003, 2, 14.

[6] a) T. Langer, R.D. Hoffmann, Curr. Pharm. Design 2001, 7, 509; b) A.C. Good, S.R. Krystek, J.S. Mason, Drug Discovery Today 2000, 5, S61; c) J. Burbaum, G.M. Tobal, Curr. Opin. Chem. Biol. 2002, 6, 427; d) R.M. Eglen, G. Schneider, H.-J. Boehm, Methods Princ. Med. Chem. 2000, 10, 1; e) H.-J. Boehm, G. Schneider, Methods Princ. Med. Chem. 2000, 10, 307; f) K. Bleicher, Curr. Med. Chem. 2002, 9, 2077.

[7] a) J. Sadowski, H. Kubinyi, J. Med. Chem. 1998, 41, 3325; b) D.F. Veber, S.R. Johnson, H.-Y. Cheng, B.R. Smith, K.W. Ward, K.D. Kopple, J. Med. Chem. 2002, 45, 2615; c) P.J. Sinko, Curr. Opin. Drug Disc. Devel. 1999, 2, 42; d) C.A. Lipinski, J. Pharm. Tox. Meth. 2001, 44, 235; e) I. Kariv, R.A. Rourik, D.B. Kassel, T.D.Y. Chung, Comb. Chem. High Throughput Screen. 2002, 5, 459; f) C.M. Masimirembwa, R. Thompson, T.B. Andersen, Comb. Chem. High Throughput Screen. 2001, 4, 245; g) J.A. DiMasi, E. Caglarcan, M. Wood-Armany, Pharmacogenomics 2001, 19, 753; h) P.J. Eddershaw, A.P. Beresford, M.K. Bayliss, Drug Discovery Today 2000, 5, 409; i) D.B. Kassel, Curr. Opinion Chem. Biol. 2004, 8, 339. 
[8] K. Bleicher, L. Green, R. Martin, M. Rogers-Evans, Curr. Opin. Chem. Biol. 2004, 8, 287.

[9] K. Bondensgaard, M. Ankernsen, H. Thorgensen, B. Hansen, B. Wulff, R. Bywater, J. Med Chem. 2004, 47, 888 .

[10] J. Perlman, A.-O. Colson, R. Jain, B. Czyzewski, C. Cohen, R. Osman, M. Gershengorn, Biochemistry 1997, 36, 15670.

[11] M. Burnier, H. Brunner, Lancet 2000, 355, 637.

[12] S. Watson, S. Arkinstall, 'The G-Protein Linked Receptors Facts Book', Academic Press, New York, 1994.

[13] D.R. Flower, Biochem. Biophys. Acta. 1999, 1422, 207.

[14] K. Bleicher, Y. Wüthrich, M. Deboni, S. Kolczewski, T. Hoffmann, A. Sleight, Bioorg. Med. Chem. Lett. 2002, 12, 2519.

[15] K. Bleicher, Y. Wüthrich, G. Adam, T. Hoffmann, A. Sleight, Bioorg. Med. Chem. Lett. 2002, 12, 3073.

[16] D. Lloyd, C. Bünemann, N. Todorov, D. Manalack, P. Dean, J. Med. Chem. 2004, 47, 493.

[17] G. Schneider, O. Clément-Chomienne, O. Hilfiger, P. Schneider, S. Kirsch, H.-J. Böhm, W. Neidhart, Angew. Chem. Int. Ed. 2000, 39, 4130 .

[18] a) P. Svenningsson, C. Le Moine, G. Fisone, B.B. Fredholm, Progress in $\mathrm{Neu}$ robiology 1999, 59, 355; b) J.-L. Moreau, G. Huber, Brain Res. Rev. 1999, 31, 65; c) S.M. Kaiser, R.J. Quinn, Drug Discovery Today 1999, 4, 542; d) K.C. Agarwal, Platelet Physiol.Pharmacol. 1999, 102; e) S.-A. Poulsen, R. J. Quinn, Bioorg. Med. Chem. 1998, 6, 619.

[19] a) R. Jakob-Roetne, C. Riemer, M. Nettekoven, W. Hunkeler, G. Huber, G. Kilpatrik, WO 0117999, 2001; b) R. JakobRoetne, C. Riemer, M. Nettekoven, W. Hunkeler, G. Huber, G. Kilpatrik, Chem. Abstr. 2001, 134, 237479.

[20] M. Nettekoven, Synlett 2001, 12, 1917.

[21] M. Nettekoven, B. Püllmann, S. Schmitt, Synthesis 2003, 11, 1649.

[22] a) K.E. Arndt, T.C. Johnson, D.G. Ouse, PCT Int. Appl. 2002, WO0238572A1; b) T.C. Johnson, R.J. Ehr, R.D. Johnston, W.A. Kleschick, A. William, T.P. Martin, M.A. Pobanz, J.C. van Heertum, R.K. Mann, US Patent Appl. 1999, US5858924; c) J.C. van Heertum, W.A. Kleschick, K.E. Arndt, M.J. Costales, R.J. Ehr, K.B. Bradley, W. Reifschneider, Z.L. Benko, M.L. Ash, J.J. Jachetta, PCT Int. Appl. 1996, WO9601826A1.

[23] B. Brodbeck, B. Püllmann, S. Schmitt, M. Nettekoven, Tetrahedron Lett. 2003, 44 , 1675.
[24] E.R. v. Beck, H. Meyer, Monatshefte Chem. verw. Teile and. Wiss. 1915, 36, 731.

[25] M. Nettekoven, G. Schneider, J. Comb. Chem. 2003, 5, 233.

[26] a) T. Kohonen, 'Self-Organization and Associative Memory', Springer, Heidelberg, 1984; b) G. Schneider, P. Wrede, Prog. Biophys. Mol. Biol. 1998, 70, 175.

[27] G. Schneider, W. Neidhart, T. Giller, G. Schmid, Angew. Chem. Int. Ed. 1999, 38 , 2894.

[28] W. Guba, M. Nettekoven, B. Püllmann, C. Riemer, S. Schmitt, Bioorg. Med. Chem. Lett. 2004, 14, 3307.

[29] K. Amin, M. Dahlstrom, P. Nordberg, I. Starke, PCT Int. Appl. 1999. WO9955706A1. CAN 131:322617.

[30] a) Gerber Molecular Design; http://www.moloc.ch; b) P.R. Gerber, J. Comp.-Aid. Mol. Design 1998, 12, 37.

[31] M.A. Johnson, G.M. Maggiora, Eds. 'Concepts and Applications of Molecular Similarity', Wiley, New York, 1990.

[32] For a more detailed description of workflow procedures, workflow concepts and automation devices utilised in the preparation of compound arrays please refer to: M. Nettekoven, A. W. Thomas, Curr. Med. Chem. 2002, 9, 2179.

[33] a) R. Mentlein, B. Gallwitz, W.E. Schmidt, Eur. J. Biochem. 1993, 214, 829; b) T.J. Kieffer, C.H.S. McIntosh, R.A. Pederson, Endocrinology 1995, 136, 3585; c) $\mathrm{H}$. Lene, C.F. Deacon, C. Orskov, J.J. Holst, Endocrinology 1999, 140, 5356; d) For a review, see J.S. Rosenblum, J.W. Kozarich, Current Opinion in Chemical Biology 2003, 7, 496.

[34] a) J.J. Holst, Gastroenterology 1994, 107, 1048; b) C. Orsakov, Diabetologia 1992, 35, 701; c) D.J. Drucker, Diabetes 1998, 47, 159.

[35] For a review, see D.J. Drucker, Expert Opinion on Investigational Drugs 2003, 12(1), 87.

[36] A.M. Abd-Elfattah, S.M. Hussain, A.M. El-Reedy, N.M. Yousif, Tetrahedron 1983, 39, 3197.

[37] J.-U. Peters, S. Weber, S. Kritter, P. Weiss, A. Wallier, M. Boehringer, M. Hennig, B. Kuhn, B.-M. Loeffler, Bioorg. Med. Chem. Lett. 2004, 14, 1491.

[38] Measurements were performed according to an in-house developed method to assess solubility from a $10 \mathrm{mM}$ DMSO stock solution. This method is similar to the classical thermodynamic shake-flask solubility with the only difference that DMSO is removed in the beginning by an additional lyophilization step. Therefore this assay is called LYophilisated Solubility Assay (LYSA).
[39] Measurements were performed according to R.S. Obach, J.G. Baxter, T.E. Liston, B.M. Silber, B.C. Jones, F. MacIntyre, D. Rance, P. Wastall, J. Pharm. Exp. Ther. 1997, 283, 46.

[40] Measurements were performed according to M. Kansy, F. Senner, K. Gubernator, $J$. Med. Chem. 1998, 41, 1007.

[41] Measurements were performed according to D.M. Stresser, S.D. Turner, A.P. Blanchard, V.P. Miller, C.L. Crespi, Drug Metab. Dispos. 2002, 30, 845 (BFC was used as a substrate)

[42] a) K. Handrock, R. Lüllmann-Rauch, R.D. Vogt, Toxicology 1993, 85, 199; b) R. Lüllmann-Rauch, R. Pods, B. von Witzendorff, B. Toxicology 1996, 110, 27; c) R.J. Mason, S.R. Walker, B.A. Shields. J.E. Henson, M.C. Williams, Amer. Rev. Respir. Dis. 1985, 131, 786.

[43] G.K. Dresser, J.D. Spence, D.G. Bailey, Clin. Pharmacokinet. 2000, 38, 41.

[44] M.J. Reasor, S. Kacew, Exp. Biol. Med. 2001, 226, 825.

[45] W.M. Meylan, P.H. Howard, J. Pharm. Sci. 1995, 84, 83.

[46] H. Fischer, M. Kansy, D. Bur, Chimia 2000, 54, 640 .

[47] a) R.J. Riley, A.J. Parker, S. Trigg, C.N. Manners, Pharm. Res. 2001, 18, 652; b) A.D. Smith, H. van de Waterbeemd, D.K. Walker, in 'Pharmacokinetics and Metabolism in Drug Design', Eds. R. Mannhold, H. Kubinyi, H. Timmermann, WileyVCH, Weinheim, 2001.

[48] H. Fischer, M. Kansy, M. Potthast, M. Csato, Proceedings of the 13th European Symposium on Quantitative StructureActivity Relationships, Duesseldorf, Germany, Aug 27-Sept 1, 2000; Prous Science: Barcelona, Spain, 2001.

[49] T. Masquelin, D. Sprenger, R. Baer, F. Gerber, Y. Mercadal, Helv. Chim. Acta 1998, $81,646$.

[50] J.-U. Peters, D. Hunziker, H. Fischer, M. Kansy, S. Weber, S. Kritter, A. Müller, A. Wallier, F. Ricklin, M. Boehringer, S. M. Poli, M. Csato, B.-M. Loeffler, Bioorg. Med. Chem. Lett. 2004, 14, 3575.

[51] Measurements were performed according to an in-house developed miniaturized method to measure the shake-flask octanol-water partition coefficient at pH 7.4 $(\log \mathrm{D})$. 